\title{
THE EFFECTIVENESS OF THE TRANSACTION SYSTEMS ON THE DAX INDEX
}

\author{
M.Sc. in Economics Marek Trembiński \\ Warsaw School of Economics, Finance and Accounting, Securities Broker \\ Assistant Professor, Ph.D. Joanna Stawska \\ Faculty of Economics and Sociology, University of Lodz \\ ORCID: https://orcid.org/0000-0001-6863-1210
}

\begin{abstract}
The purpose of the article/hypothesis: The aim of this article is to examine the effectiveness of trading systems built on the basis of technical analysis tools in 2015-2020 on the DAX stock exchange index. Efficiency is understood as generating positive rates of return, taking into account the risk incurred by the investor, as well as achieving better results than passive strategies. Presenting empirical evidence implying the value of technical analysis is a difficult task not only because of a huge number of instruments used on a daily basis, but also due to their almost unlimited possibility to modify parameters and often subjective evaluation.

Methodology: The effectiveness of technical analysis tools was tested using selected investment strategies based on oscillators and indicators following the trend. All transactions were carried out on the Meta Trader 4 platform. The analyzed strategies were comprehensively assessed using the portfolio management quality measures, such as the Sharpe measure or the MAR ratio (Managed Account Ratio).

Results of the research: The test results confirmed that the application of described investment strategies contributes to the achievement of effective results and, above all, protects the portfolio against a significant loss in the period of strong turmoil on the stock exchange. During the research period, only two strategies (Ichimoku and ETF- Exchange traded fund) would produce negative returns at the worst possible end of the investment. At the best moment, however, the „passive” investment achieved the lowest result. Looking at the final balance at the end of 2019, as many as four systems based on technical analysis were more effective than the „buy and hold" strategy, and at the end of the first quarter of 2020 - all of them. When analyzing the management quality measures, it turned out that taking into account the 21 quarters, the passive strategy had the lowest MAR index. The Sharpe's measure is also relatively weak compared to the four leading strategies.
\end{abstract}

Keywords: technical analysis, trading systems, DAX index, stock exchange, investment strategies.

JEL Class: G11, G14, G15, O24. 


\section{INTRODUCTION}

Technical analysis is one of the oldest areas of market science although many investors and academics see it as a useless tool in making investment decisions, and even as ,reading tea leaves” or a self-fulfilling forecast. Meanwhile, one of the fundamental aspects of technical analysis is the study of market behavior by using charts to predict future price levels in the light of rapidly changing human perception, which determines quick actions that would not be possible using only the fundamental analysis. In order to fully appreciate the technical analysis, it is first of all necessary to understand its assumptions, which are based on three rational pillars. The first one tells us that the market discounts everything. This means that all political, fundamental or psychological factors affecting the market price of a commodity are fully reflected in the price of that commodity, and therefore, studying price behavior is a self-sustaining approach. Perhaps this approach seems to be an oversimplification, but after much reflection it is hard to disagree with it. The second premise is that prices are trending. Studying the charts comes down to identifying trends at an early stage, enabling us to trade in line with their direction. Moreover, trends tend to continue running in the current direction, rather than change, until there are significant signs of a possible reversal. The third pillar is based on patterns proven in the past and is based on the study of the human psyche, which remains unchanged. This means that history likes to repeat itself, so an important factor in understanding the future is the proper analysis of historical quotations [Murphy 1995: 2-4]. Technical analysis has many strengths, but limitations as well. A big plus is the fact that it is based on historical data such as prices, volume or a number of open positions. This information is publicly available, which allows market participants to relatively easily translate it into a chart and analyze it. Thanks to the above data, it is possible to determine not only the liquidity of a given stock, but also to set support and resistance levels as well as trend lines. Moreover, technical analysis is a universal method, regardless of whether we study the market of raw materials, shares, currencies or precious metals. Another advantage is the application for any investment horizon although it is the most popular among short-term players. Contrary to the fundamental analysis, specialist knowledge on the interpretation of financial statements is also not required, which, when using creative accounting or placing given assets or liabilities in a different category, may have a negative impact on the company's reliable valuation.

Critics of technical analysis point out the lack of correlation between historical and future prices. As a result, the tools used in the past do not have to prove useful in the future, leading investors to lose trades [Pająk 2013: 132-134].

In some situations, we also receive contradictory information that is mutually exclusive - namely, one indicator gives a sell signal and the other gives a buy 
signal, which makes it difficult to take a position on the right side of the market. Among the disadvantages (or perhaps advantages?) of the analysis, there is also a significant element of subjectivism, while the fundamental assessment of values is related to the interpretation of economic and financial data. Meanwhile, the subjective approach leads to a heuristic error, called the ,backward thinking effect". For this reason, the layouts on the chart play out completely differently in retrospect than at the time of trading [www5, accessed 2.02.2020]. The article consists of the following parts: introduction, the theoretical part in which the researched investment strategies are described, and then the empirical part in which the effectiveness of a total of six transaction systems built on the basis of technical analysis was checked, using two selected measures of portfolio management quality, i.e. the Sharpe indicator and MAR, and then additionally compared the previously tested six trading systems with the passive ,buy and hold" strategy also using the Sharpe and MAR ratios. The article ends with conclusions of the conducted study.

\section{CONSTRUCTION OF TRANSACTION SYSTEMS}

Many novice investors are looking for a magic indicator that will allow them to multiply their capital. When it starts to work, they feel as if they have discovered the Holy Grail and the path to success seems simple. The reality can be quite different, however, as markets are too complex to be analyzed using only one measure. Hence, this article will examine six trading systems created on the basis of technical analysis, such as: 1) the strategy of moving averages and ADX indicator; 2) MACD and Parabolic SAR strategy; 3) the strategy based on RSI and Bollinger bands; 4) Ichimoku Kinko Hyo Technique; 5) the strategy using Commodity Channel Index and Donchian Channel; 6) the strategy based on the stochastic oscillator and the Keltner Channel, and then comparing them with the passive strategy, i.e. ,buy and hold”. Before these strategies were compared by using the Sharpe index and MAR, the structure of the analyzed strategies is presented below.

\subsection{Moving averages strategy and ADX indicator}

Each investment strategy requires not only setting a convenient entry point, but also an exit from the position in order to properly manage risk. Moving averages are used to detect long-term trends as well as day trading. They smooth out market vibrations and short-term volatility of quotations, which allows us to identify where the market is heading. On the other hand, they do not work for 
consolidation, generating many wrong signals. They also do not measure the strength of the current trend [LeBeau and Lucas 1998: 90-92].

One of the simplest and one of the most effective systems is the one moving average system. The buy signal occurs when the rate crosses the average line from the bottom, and the sell signal occurs when the rate crosses the average line from the top. It is a simple system that implies a continuous presence on the market, but it is worth using additional filters [LeBeau and Lucas 1998: 96-97; Borowski 2019]. However, the system based on two averages is used more often. Various combinations of $\mathrm{N}$ values are possible, e.g. 3- and 12-period mean or the popular Richard Donchian system based on 5 and 20 periods. The principle of using averages is simple: we buy when the shorter average (faster) crosses the slower average from the bottom. We do the opposite while opening a short position.

In order to build a better and more comprehensive system, it is worth adding the Directional Movement Index (DMI) to the moving averages. The structure of the system was proposed by J. Welles Wilder in the 1970s. The method not only identifies the current trend, but also provides information whether it is fast enough to be worth following. The DMI indicator consists of three lines [www16, accessed 27.02.2020]:

- ADX (Average Directional Movement Index),

- DI+ (Directional Indicator +),

- DI- (Directional Indicator -).

Directional movement is the range of price fluctuations in a given period that is outside the extremes of the previous period. For example, if today's price range is above yesterday's, then the directional movement is positive (+DM), if below negative $(-\mathrm{DM})$. If today's trading range is within yesterday's range or is symmetrically above and below it, then $\mathrm{DM}=0$ (no movement). After determining the directional movement, it is necessary to calculate - swing range - the so-called true range. TR is the largest of the three values::

- the difference between today's - maximum and minimum or

- today's maximum - and yesterday's closing price

- today's minimum and yesterday's closing price.

To calculate the daily directional indicators (+DI) and (-DI), divide (+/-) the DM by the TR, thanks to which the directional traffic is presented as a percentage value in relation to the range of fluctuations on a given day. Subsequently, the lines should be smoothed using e.g. a 13-day moving average. When +DI13 is above -DI13 we are dealing with an uptrend, if it is below - with a downtrend. Buy or sell signals are generated when the lines cross. At the end, the ADX (smoothed DX) indicator is calculated, which goes up when prices are moving in one specific direction [Elder 2018: 136-138]. The DX directional index is determined by the following formula: 


$$
\mathrm{DX}=\frac{(+\mathrm{DI} 13--\mathrm{DI} 13) \times 100}{+\mathrm{DI} 13+-\mathrm{DI} 13}
$$

In the literature, the value of the ADX indicator below 20 points is considered a weak trend, therefore, other indicators should be used. As the ADX level rises, traders should be driven by trend following systems (e.g. moving average). A reading above 45 points indicates a very strong trend and increases the probability of a correction [Borowski 2018: 127].

The ADX can be used as a filter with a strategy based on two moving averages or the crossing of the $+\mathrm{DI}$ and $-\mathrm{DI}$ lines, which can also be used to play against the trend. A sell signal appears when the +DI line reaches extremely high values (e.g. 40 points) and the -DI line shows extremely low values (below 10 points) [www12, accessed 27.03.2020]. The disadvantage of the ADX indicator is that it only starts to increase after the + DI and -DI lines intersect.

\subsection{MACD and Parabolic SAR Strategies}

Indicators, commonly called oscillators, allow you to pinpoint the stage of a trend and pinpoint the moment when the trend loses its momentum. They have been applied in technical analysis because they express the pace at which market prices change. Strong momentum suggests a healthy trend, a weak one warns that the price movement may end. Extreme momentum values can accompany short-term depletion moments, showing overbought or oversold conditions, which increases the likelihood of a correction.

The MACD indicator is primarily popular with traders because of its great flexibility as a tool to play with and against the trend. It was constructed by Gerald Apple and presents the difference of two exponential moving averages (12 and 26 EMA) together with a 9-period mean of this difference, which is the signal line. The result is a smooth oscillator with a wide range of applications. Trade opening signals are generated by breakout of the zero line, crosses of the signal line, oversold and overbought situations as well as divergences. The convergence and divergence of the moving averages reflect the approaching or receding of the averages depending on the speed and changes in the direction of the rates [Etzkorn 1999: 33].

The sell signal is generated when the MACD fast line crosses the signal line from above, both of them being positive. The signal is all the more important the higher the intersection above the zero line occurs. Thus, breakthroughs below line 0 should be ignored. A buy signal will appear in the opposite way. Similarly, the lower the intersection below the 0 line, the more reliable it is. It should also be remembered that, unlike other oscillators such as the RSI or the stochastic 
oscillator, the Moving ACD has no lower or upper fluctuation limits [Bar 2001: 108-109].

The MACD is an indicator of an auxiliary nature and its application should be subordinated to the basic trend analysis. It can generate a lot of false signals in the initial phase of a trend, so it is better suited at the end of mature trends. Such information can be provided by a positive or negative divergence. For example, a negative divergence occurs when the MACD lines are well above the 0 level and begin to decline while prices continue to hit new maximus. This is often a warning that a price peak is forming [Murphy 2017: 232].

The strategy may be complemented by the Parabolic Stop and Reversal indicator developed by Wells Wilder, which performs very well in clear vertical trends. The PSAR is obviously an indicator of the prevailing trend direction, but it also proves to be useful in targeting levels of defense orders. It is rarely used as a single tool, but usually in building simple trading systems in conjunction with oscillators [www7, accessed 30.03.2020]. The very name of the indicator comes from the arrangement of dots placed above and below the prices of the instrument, the shape of which resembles a parabola. To calculate the value of the indicator, the following recursive formula is adopted [www2, accessed 28.02.2020]:

$$
\text { PSARt }=\text { PSARt }-1+\text { AFt }-1 \times(\text { EPt }-1-\text { PSARt }-1)
$$

where:

PSARt - the value of the Parabolic parameter at time t,

$\mathrm{AF}$ - the acceleration factor that increases when a new high is reached for long positions or a new low is for short positions. Wilder's proposed value is 0.02 , increasing in 0.02 steps until it reaches $0.18-0.21$,

$\mathrm{EF}$ - lowest or highest price recorded in the current trend.

It should be remembered that in a sideways trend the indicator is practically useless. Then it provides delayed signals, which, due to the low volatility of price movements, makes it difficult to conduct profitable transactions [Borowski 2017: 114].

In the above strategy, the condition for opening a long position is that the MACD indicates an uptrend and the position of the parabolic dot under the price. Conversely, in case of opening a short position the parabolic should be above the price and the MACD oscillator should indicate a downward movement. In addition, traders often use the PSAR as their stop loss level, which is set at the last dot. When the trend accelerates, the dots begin to move away from each other, which allows us to hedge unrealized gains. 


\subsection{Strategy based on RSI and Bollinger Bands}

Another strategy commonly used in the financial markets consists of the Relative Strength Index (RSI) oscillator and Bollinger bands. This is one of the contrarian strategies because it involves opening positions against the current trend despite the famous saying among traders - „the trend is your friend”.

The RSI belongs to the group of momentum indicators which inform investors about the strength and maturity of the current market trend. It was developed by the aforementioned J.W. Wilder in the 1970s. The indicator illustrates the relationship between upward and downward movements in closing prices in a given period, and then normalizes the results so that the index values vary between 0 and 100 . The methodology for calculating the RSI value is defined by the following formula [Nowakowski 2003: 58]:

$$
\mathrm{RSI}=100-\frac{100}{1+\left(\frac{\mathrm{Ui}, \mathrm{n}}{\mathrm{Di}, \mathrm{n}}\right)},
$$

where:

$\frac{\mathrm{Ui}, \mathrm{n}}{\mathrm{Di}, \mathrm{n}}=$ (average of positive price changes in $\mathrm{n}$ sessions) / (average of negative price changes in $\mathrm{n}$ sessions).

A quotient of sums can also be used instead of quotient of means. Wilder himself proposed exponential means although analysts use other averages as well. Most often, 9, 14 or 21 periods are taken as n, and the longer the period, the fewer signals the oscillator generates. When making investment decisions while taking into account the RSI, investors pay attention to emerging divergences and levels of oversold and overbought. Divergence occurs when the RSI starts to decline despite further price increases and the next peak of the indicator is below the previous one. Usually, the overbought level is defined when the index exceeds 70 , but during a bull market, the value of 80 can also be adopted. The oversold zone is bounded by the level of 30 or 20 points [Czekała 1997: 57].

When an indicator enters an overbought or oversold zone, it is a warning signal of a possible trend reversal, but relying solely on the relative strength index can lead to huge losses. This is because in a bullish or bearish period, the RSI is often in the overbought or oversold zone for a long time, so it is important to use it in conjunction with another technical analysis tool [Czekała 1997: 59]. The oscillator gives quite good signals when a given value is in a horizontal trend. In this case, a buy signal is generated when the indicator rises above the oversold level, and a sell signal is generated when the index drops below the overbought level. 
Unlike most indicators, Bollinger Bands is not a static indicator and changes its shape based on recent prices and accurate measurement of momentum and volatility. The very mechanism of this tool is relatively simple. The middle line is a moving average, usually calculated for the closing prices of subsequent sessions. The other two lines are separated by a certain number of standard deviations of quotations for the adopted period. Typically a 20-period moving average and two standard deviations are used. These are not randomly established parameters as they have strong statistical foundations. The three-sigma law tells us that $68.2 \%$ of the observations are within $+/-1$ deviation from the mean, while among the 2 deviations the probability increases up to $95.4 \%$. In the range of 3 deviations, it is $99.7 \%$ of observations [www1, accessed 3.03.2020].

In periods when the market is in a sideways trend, it should move between extreme bands. Reaching the bottom line is then treated as a buy signal, conversely, a sell signal appears near the upper band. As the volatility increases, the bands will deviate more and more from the moving average. Additionally, while setting the standard deviation, multiplicity parameter at the level of 2.5 results in the fact that the price reaches the lower or upper band less often, which makes the meaning of such a signal more reliable [Kochan 2009: 208 209].

A lot of information from Bollinger Bands can be used to analyze the strength of a trend. During strong trends, the price stays close to the low or high line, and a pullback when the trend continues indicates a weakening momentum. On the other hand, repeated attempts to get the course close to the outer rim, which fail signal a lack of strength [www8, accessed 2.04.2020].

The strategy based on the Bollinger bands and the RSI oscillator generates a sell signal when the price reaches the upper band and is rejected there, while the relative strength index is in the overbought zone. The occurrence of divergence may also be an additional confirmation. A buy signal is generated inversely. We buy when the price bounces from the bottom line and the RSI oscillator shows a value below 30 . The unquestionable advantage of the strategy is the combination of the leading indicator (RSI) with the lagging indicator (BB). The disadvantages include the fact that if you rely on a contrarian strategy, without the proper setting of defense orders, you can suffer severe losses. Corrective movements are shallower than directional movements, which limits their potential.

\subsection{Ichimoku Kinko Hyov Technique}

This strategy that literally translates to „one glance equilibrium chart" was developed in 1968 by Goichi Hosoda. Ichimoku and consists of 5 lines [Bąk 2015: 36]: 
- conversion line - tenkan sen,

- base line - kijun sen,

- lagging line - chikou span,

- leading span A - senkou span A,

- leading span $B$ - senkou span B.

The conversion line is the average of the high and low over the last 9 periods (e.g. the last 9 day candles). Usually, it is closest to the current price and sets the first support or resistance level when a correction occurs.

Kijun sen is calculated in the same way as tenkan sen, but takes into account the last 26 periods. After the return line, it is another, but definitely stronger, resistance or support.

The chikou span is a line that represents the current closing price but shifted back 26 periods. The principle is as follows: when it is above the price, it is an uptrend, if below the price - it defines a downward trend. The delayed line does not generate trading signals, but is a perfect complement to other indicators [www14, accessed 15.03.2020].

The first of the lines forming the so-called Ichimoku (Kumo) cloud is senkou span $A$. It is calculated by adding tenkan and kijun values together, then dividing the sum by 2 and shifting it forward 26 periods, whereby it is classified as a leading indicator. In other words, it provides information about the future potential behavior of the course. The second line, senkou span B, is the result of calculating the average of the maximum and minimum 52 candles and also shifting by 26 periods forward. The area between them is called the cloud, and depending on which senkou line is higher, it is called an upward or downward cloud. Span B often remains flat. Kumo provides the investor with a lot of information. The cloud can be rising (Span A above Span B) and falling (Span A below Span B). The thickness of the cloud is also important. The thicker it is, the less likely it gets that the rate will break its level and the current trend will be reversed. Moreover, it works very well as support and resistance levels [Elliott 2007: 36-40].

A strategy based on the first two lines can generate three signals: strong, neutral and weak. A strong buy signal is generated when tenkan sen pierces from below the Kijun sen above the cloud. A similarly strong sell signal occurs when tenkan sen crosses the top of the kijun sen below the kumo. Neutral is observed when the lines intersect within the cloud. It shows that investors are indecisive and the rate may exit from consolidation both upwards and downwards. A weak buy signal occurs when the cross occurs below the cloud, which is treated as a strong price resistance. The interpretation of the line arrangement is the same as in the case of the strategy based on two moving averages. Another impulse for stock exchange players is the price going out of the cloud. Long positions should be opened when the candle closes above the cloud. Conversely, we open short 
positions - when the candle's closing is below the kumo. The third buy signal is the behavior of the chikou span line with respect to price. If the lagging line crosses the price or goes above it, it confirms the current uptrend in the market. Therefore, we do not buy when the chikou span is below the rate. Similarly, we do not open positions when candles are drawn in the cloud range, as this proves that the consolidation prevails on the market [Oziemczuk 2011: 61-63].

Therefore, the strongest buy signal is to take a long position when three conditions are simultaneously met: 1) Tenkan sen crosses kijun sen from the bottom above kumo; 2) the rate will go above the cloud (the higher the more reliable the break); 3) Chikou span is above the price.

The Ichimoku technique is applicable in all financial markets: stocks, bonds, commodities, currencies or indices [Borowski 2001: 3].

\subsection{Strategy using the Commodity Channel Index and the Donchian Channel}

The CCI oscillator was created by Donald Lambert and first described in 1980. Initially, it gained the popularity mainly on commodity markets, but over time it began to be used also in other markets. The indicator is used to trade with the trend, but because it acts like an oscillator, it can also be used to identify turning points [Frierdich 2013: 256].

CCI is based on a mathematical formula, the result of which is a value that expresses the statistical distance between the price of a given asset and a moving average. When the distance is relatively large, we assume that a trend has formed, and we open a position in its direction. The formula for calculating the CCI value is as follows [www3, accessed 24.04.2020]:

$$
\mathrm{CCI}=(\text { typical price }- \text { moving average }) /(0,015 \mathrm{x} \text { mean deviation })
$$

According to the author's concept, a typical price is nothing more than the arithmetic mean of the following three values: highest, lowest and closing. As for the moving average, it was originally calculated on the basis of 20 periods, but is now more and more often based on 14 periods. In the denominator, Donald Lambert took the constant value of 0.015 so that most of the observations fell in the range of -100 to +100 . The CCI can therefore be positive or negative. The author of the indicator signaled the opening of long positions when the oscillator exceeded +100 points and their closing when it fell below this round limit. On the other hand, short positions should be concluded after exceeding the level of -100 points and closed when returning to the -100 line. This approach, however, has quite a significant disadvantage, namely overlooking the entire initial phase of the emerging trend. Therefore, in the literature, we can meet with recommendations 
to open long position after breaking the 0 level from the bottom and the short position after crossing from the top [www13, accessed 15.04.2020].

The formula of the Donchian Channel is relatively simple. The upper band is the maximum, and the lower band is the minimum of the last $\mathrm{n}$ periods. The presumed value of the $n$ parameter on most trading platforms is 20 , but it can be modified depending on the investment horizon and the financial instrument. As a rule, a buy signal is generated when the rate is above the current level of the upper band. Short positions should be opened when the price is below the most recent reading of the lower band of the channel. Therefore, the Donchian-based trading system assumes that positions should be concluded when a significant support or resistance breaks. If we want to trade on the basis of the arithmetic mean of external bands, the trading signals are analogous to the moving average [www17, accessed 28.03.2020].

An exemplary trading system based on the CCI and Donchian Channel may generate a buy signal when the rate breaks the upper limit of the channel and the CCI exceeds the 100 points limit. To capture most of the traffic, it is enough for the CCI to show a positive value, but this reduces the reliability of the indicator.

\subsection{Strategy based on the stochastic oscillator and the Keltner Channel}

In spite of the fact that the very word ,stochastic" refers to the randomness that every investor tries to avoid in analyzing financial markets, the stochastic oscillator is one of the most widely used tools. It was developed by George Lane in the late 1950s. The stochastic oscillator concept assumes that during a strong upward trend, closing prices will run around the highs recorded during a given session, while in a downtrend - near lows. Similar to the RSI, the tool identifies overbought and oversold levels, indicating the exhaustion or potential of the current trend. The indicator is constructed using two lines $-\% \mathrm{~K}$ and $\% \mathrm{D}$. The first of them is the so-called the „fast oscillator”, the second - is known as „slow oscillator". The $\% \mathrm{~K}$ line measures the strength of a price movement compared to the price range over a given period. To calculate the value of the fast $\% \mathrm{~K}$ oscillator, you need to calculate the difference between the last closing price and the minimum price from e.g. the last 5 sessions. We divide the obtained result by the difference between the highest and the lowest value recorded during the tested interval (in this case 5 sessions). In order to get a value from 0 to 100 , the quotient is multiplied by 100 . The levels of overbought and oversold are defined in the same way as for the RSI oscillator, so we need the second $\% \mathrm{D}$ line to refine the indicator. There is a 3-period simple moving average of the $\% \mathrm{~K}$ line and is most often shown as a dotted line on trading platforms. Using both lines we get a more reliable indicator that generates buy and sell signals every time the $\% \mathrm{~K}$ line 
crosses the $\% \mathrm{D}$ line. The best signals are in the oversold or overbought zone. A long position should be open when, in the oversold zone, the $\% \mathrm{~K}$ line crosses the $\% \mathrm{D}$ line from the bottom. A short position, on the other hand, when the $\% \mathrm{~K}$ line crosses the $\% \mathrm{D}$ line from the top at overbought levels. Analyzing the course of a stochastic oscillator can also provide other valuable information, such as a bullish or bearish divergence. We encounter the former when prices set lower and lower lows, while the stochastic begins to rise. If the stochastic oscillator goes down when prices start to rise, it is a bearish divergence. In both situations, a warning appears about a possible reversal of the current trend [Rockefeller 2012: 267-270].

The author of the second indicator is Chester Keltner, known as a commodity trader. While the Keltner Channel may resemble the more well-known Bollinger Bands in the technical analysis theory, in reality its use and design differ from the Bollinger Bands described above. The main difference is that the outer bands do not rely on standard deviation but use a different measure of volatility, which is ATR - Average True Range, developed by J. Wilder. So the price swing range is just a number, so we need to average the TR over several days to get the ATR. The increase in this indicator tells us about the greater volatility in the market. For his calculations the author of the tool used the 14-session moving average [Jabłoński 2006: 32].

Returning to the design of the Keltner Channel, however, the middle line is the 20-day exponential moving average. To plot the lower and upper band, we subtract and add the ATR value multiplied by the coefficient, which, according to the literature, should be 2 although it can be modified for a given instrument. The greater the value of the coefficient, the wider the channel and vice versa. Investors use the Keltner Channel in two ways. The first one involves playing „from band to band" and works best during consolidation. The second way is to open a position after breaking the outer band, which confirms the strength of the current trend. When the price closes over the high band, a buy signal is generated. When the price closes below the lower band, we open short positions [www15, accessed 20.03.2020]. However, the breakout strategy should be supplemented with e.g. ADX.

The above strategy based on the stochastic oscillator and the Keltner Channel may suggest opening a long position when in the oversold zone the $\% \mathrm{~K}$ line breaks the $\% \mathrm{D}$ line from the bottom and the price broke below the bottom band of the channel and starts to come back to it. Short - when the \% K line crosses the top of $\% \mathrm{D}$ in the overbought zone and the price is above the upper band of the channel.

The trading systems described above are examples of technical analysis indicators that can be freely modified not only in terms of the size of the parameters, but also their skillful replacement. 


\section{TESTING OF TRADING SYSTEMS ON THE DAX STOCK INDEX}

DAX (Deutscher Aktienindex) is the main German stock index, which includes 30 largest companies whose total capitalization accounts for nearly $80 \%$ of all companies listed on the German stock exchange. Its components include such companies as Adidas, Deutsche Bank, Lufthansa, Volkswagen, Bayer and Siemens. While calculating the value of the index not only is the increase in prices taken into account but also dividends paid, so unlike the Polish WIG20, it is a return index. The first quotations date back to July 1, 1988, from the level of 1163.52 points, setting the base of 1000 points as of December 31, 1987 [www6, accessed 10.04.2020].

The index itself is not an asset that can be bought directly. Other investment alternatives based on the DAX index can include CFDs (their price may depend directly on the value of the index or futures contract), options or replication of the company's portfolio in appropriate proportions.

\subsection{Research methodology}

Due to the specificity and rolling over of subsequent series of futures contracts, the study will be conducted on an index-based CFD. For the standardization of calculations, the value of one point is EUR 25, i.e. as much as the multiplier of the futures contract. The scope of the test covers the quotations from the beginning of 2015 to March 30, 2020, thanks to which the period of the outbreak of the coronavirus pandemic will also be taken into account, during which the market experienced huge turbulences.

All transactions were carried out on the Meta Trader 4 platform using the simulator provided by the Admiral Markets broker. Trading on the simulator is carried out in the same way as on the real market in real time, therefore backtesting allows for quite an effective confrontation with the market. After the test is completed, a report is generated and it shows a lot of additional data, such as the number of profitable and losing positions or the capital curve during the investment period. In addition, the sample report includes:

- Total net profit - the final result of all transactions, calculated as the difference between ,gross profit” and ,gross loss”;

- Gross profit - sum of all profitable items;

- Gross loss - the sum of all losing positions;

- Profit ratio - quotient of gross profit and gross loss;

- Expected profit - a parameter reflecting the statistical average of the profit /loss ratio for one transaction; 
- The curve of capital - that is reflected in the account balance during the life of the investment.

The overall results presented in the reports allow for a quick overview of the results of individual strategies.

Each of the transactions was concluded on the basis of the chart analysis on the daily interval. The spread, i.e. the difference between the bid and ask price, was 1 point, which corresponds to the offer made by most brokers. The negative swap points that are charged daily as a cost-holding for index based CFDs are included in the trading results. Moreover, for the sake of simplification, the unlimited market liquidity was adopted and all open positions are buy transactions.

The starting balance for a single strategy is EUR 50,000. Assuming that the margin is fixed and constitutes $5 \%$ of the nominal value, in the case of the average rate of 10,000 points and a multiplier of 25 euros, its value fluctuates around 12,500 euros. Given that the stop-out mechanism, i.e. automatic closing of the position by the broker, occurs when the valuation of the account drops to $50 \%$ of the required margin, the investor may „lose” 1,750 points.

\subsection{Trading systems results}

The first strategy tested was a system based on two moving averages and the ADX index (SMA20; SMA5; ADX14). Long positions were opened when three conditions were simultaneously met: the faster moving average crossed the slower average from the bottom, the +DI line was above -DI and the ADX indicator was higher than 25, indicating a relatively strong uptrend. The exit from the market took place as the faster average fell below the slower one, suggesting an impending technical correction.

In the period from January 1, 2015 to March 30, 2020, the system generated 26 buy signals. Profitable trades accounted for $50 \%$ of the total for a gross profit of $€ 129,124$ with a gross loss of $€ 81,963$. As a result, the total net profit (excluding taxation) was 47,161 euros. The largest profitable trade allowed the investor to earn EUR 30,827, while the average profitable trade was EUR 9,932. Likewise, the most losing position depleted an investor's portfolio by $€ 11,813$, with an average loss transaction of $€ 6,304$. The profit ratio is calculated as the ratio of gross profit to gross loss 1.58 , while the expected profit on one transaction is approximately EUR 1,814.

The capital curve during the entire investment period is presented below. 


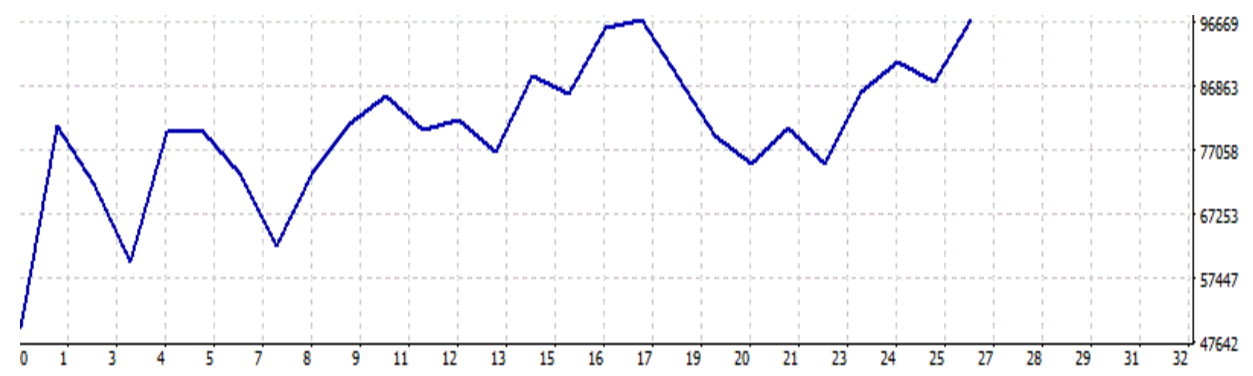

Figure 1. Capital curve for the SMA - ADX strategy

Source: own elaboration.

It is worth noting that the account balance not even once fell below the initial deposit of EUR 50,000, so all loss positions only reduced profits and not invested capital. The final account balance is 97161 euros.

The next investment strategy was based on MACD and Parabolic SAR (EMA12; EMA26; MACD SMA26; AF = 0.01; $\max 0.2$ ). The buy signal was generated when the price was above Parabolic with simultaneous MACD readings above the 0 line. Positions were closed when the index was below the Parabolic dot. In order to generate fewer false signals, the acceleration parameter was set at 0.01 .

For nearly 5 years, the strategy gave 35 buy signals. Profitable transactions accounted for less than $43 \%$ of all items, bringing a gross profit of EUR 152586 with a gross loss of EUR 143768 . The total net profit was 8,818 euros. The most successful transaction was EUR 21,536, while the average profitable transaction was EUR 10,172. On the other hand, the most losing position depleted the account balance by EUR 13,284 with an average loss transaction of EUR 7,188. The profit ratio showed a value of 1.06 , while the expected profit on one transaction is around EUR 252.

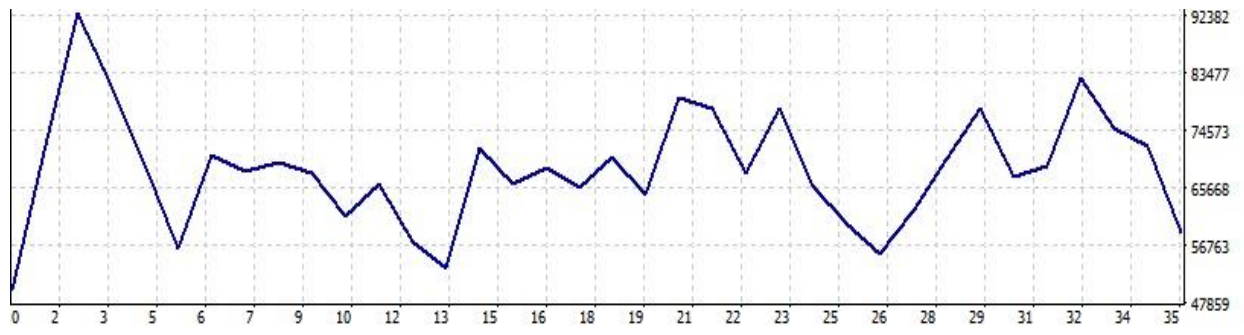

Figure 2. Capital curve for MACD - PSAR strategy

Source: own elaboration. 
As in the case of the first trading system, the investor did not have to face a reduction in invested capital, as the balance of the operating register never fell below the threshold of EUR 50,000 although as a result of two losing positions in the second half of 2016, the balance fell to a record low level 53290 euros. The account balance as of March 30 this year is EUR 58818.

The third trading system used information from the RSI oscillator and Bollinger Bands ( sigma = 2; SMA20; interval = 5; oversold-buy-in: 30-70). The buy signal was generated when the oscillator was returning from the oversold zone (from levels below 30 points) and the rate was ,,rebounding” from the lower Bollinger band. The position was closed when the quotes returned from the middle or top band. The rejection was considered to be at least two downturn candles on the daily interval. In the event that the rate did not even approach the simple moving average, a defensive stop loss order was placed, located slightly below the last local lows.

The system provided 44 buy signals throughout the research period. The number of profitable transactions as well as the loss ones was 22 . The gross profit was 207,638 euro with the gross loss of 134,394 euro. The total net profit was therefore EUR 73243 . The single transaction on which the investor could earn the most was opened on January 29, 2015 and allowed to realize a profit of EUR 28,651, while the average profitable transaction is EUR 9,438. The most losing position reduced profits by EUR 12,003 with an average loss transaction of EUR 6,109. The profit ratio showed a value of 1.54, while the expected profit per transaction is approximately EUR 1,665.

As when testing the two previous systems, the investor did not have to worry about reducing their initial balance.

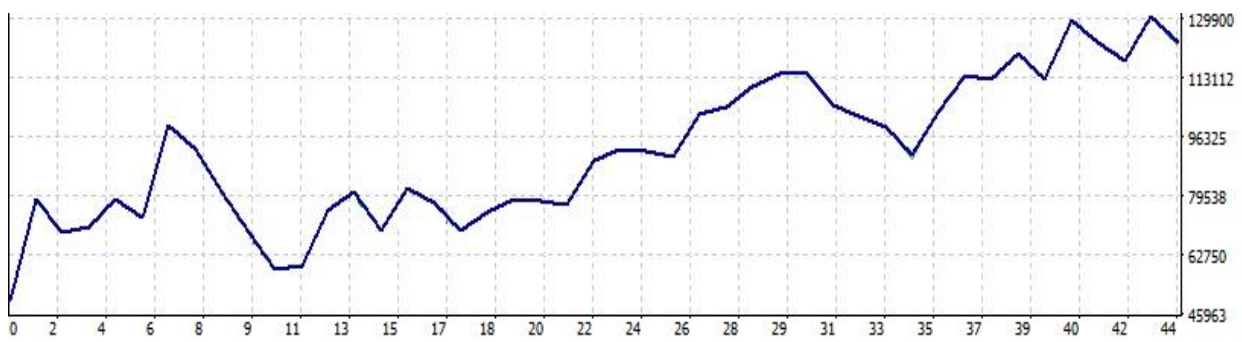

Figure 3. Capital curve for the Bollinger Bands strategy - RSI

Source: own elaboration.

Looking at the capital curve, it can be concluded that the strategy, except for two weaker periods, allows you to generate systematic profits. Moreover, it allowed to stay out of the market during this year's stock market crash. Ultimately, the account balance on March 30, 2020 oscillated around EUR 123,240. 
The Japanese system based on the discovery of Goichi Hosoda (tenkan = 9; kijun $=26$; senkou $=52$; chikou $=26$ ) gave the green light to open a long position when several conditions were simultaneously met. Tenkan-sen had to be above kijun-sen, index rate above cloud and chikou-span line above price. The position was closed if the tenkan line broke through the kijun line from the top or the quotes went below the kumo.

The Ichimoku Kinko Hyo technique has only been used 22 times over a five-year period, 12 of which are profitable (54.55\%). The first of them turned out to be the most profitable (EUR 39,844), but the maximum balance later exceeded EUR 90,000. The gross profit was EUR 124,216 and the gross loss was EUR 113,697, resulting in a net profit of EUR 10,519. The most losing position reduced the value of the portfolio by EUR 17823 with an average loss transaction of EUR 11 370. A fairly low reading showed a profit ratio of 1.09 as well as a projected profit of EUR 478.

The capital curve is as follows.

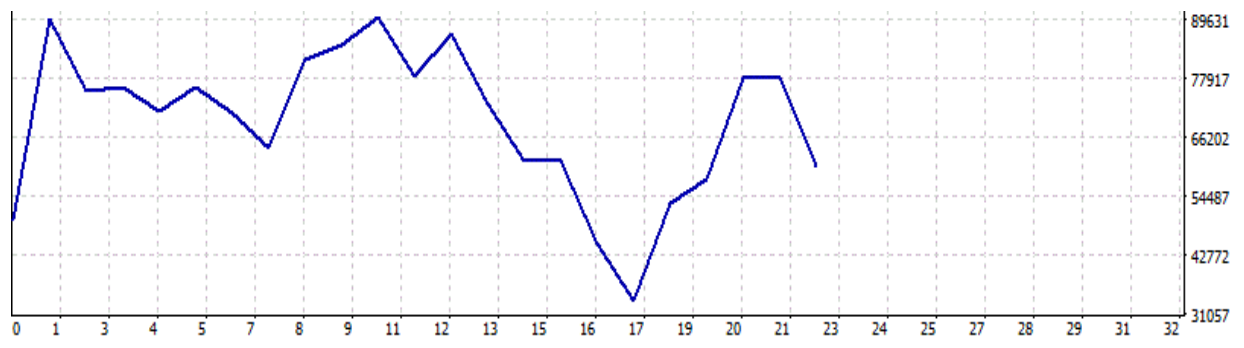

Figure 4. Capital curve for Ichimoku strategy

Source: own elaboration.

Although the system allowed to generate profit during the investment period, some attention should be paid to its failure during the first three quarters of 2018 , leading to a decrease in capital towards EUR 33,875. The final value of the portfolio at the end of the research period was EUR 60,520.

The fifth strategy was based on the Donchian channel and the CCI oscillator (Donchian $n=20$; CCI $n=20$; typical price $=H L C / 3$ ). The system assumed connecting to the existing trend, therefore, in order for a long position to be opened, the CCI oscillator should go above 100, and the rate should break the upper band of the channel. Positions were closed relatively quickly when the CCI started to return below the level of 100 , so it was unnecessary to set a defensive stop loss order.

Since the beginning of 2015 , the system has generated as many as 45 buy signals. Profitable trades only accounted for $37.80 \%$ of all items, but the gross 
profit of EUR 118,375 exceeded the gross loss (EUR 85,005). As a result, the total net profit was EUR 33,369. The largest profitable transaction allowed the investor to earn EUR 23,602, while the average profitable transaction oscillated around EUR 6,963. The most unsuccessful investment depleted the investor's portfolio by EUR 9,350 with an average loss transaction of EUR 3,036. The profit ratio was 1.39, while the expected profit on one transaction is around EUR 742.

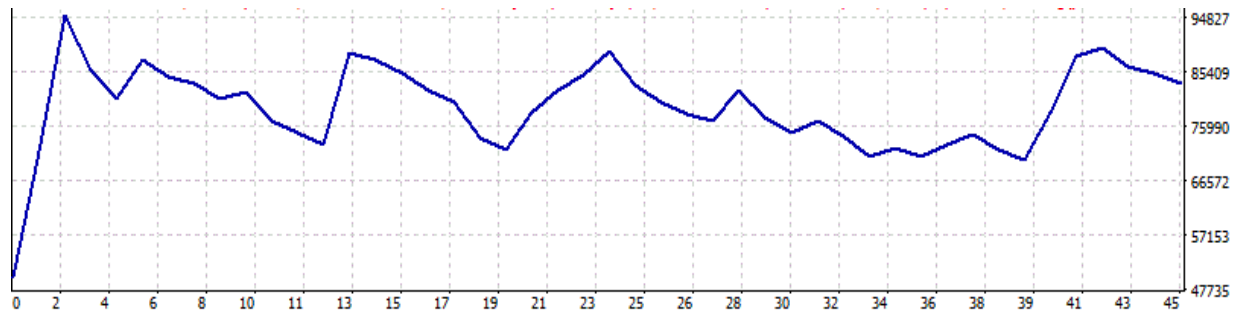

Figure 5. Capital curve for the Donchian Channel - CCI strategy

Source: own elaboration.

When analyzing the capital curve, it should be emphasized that the investment could provide the investor with mental comfort. Not only did the system not contribute to a reduction in the initial balance, but not even once the account balance fell below EUR 70,000. The final balance of the account is EUR 83,369.

The last trading system using a stochastic oscillator and a Keltner Channel $(\% \mathrm{~K}=5 ; \% \mathrm{D}=3$; EMA20; ATR period $=10$; ATR multiplier $=2)$ is a typical contrarian strategy. The investor should open long positions when the rate rebounded from the bottom band of the channel and the faster \% $\mathrm{K}$ line breaks the slower $\% \mathrm{D}$ in the oversold zone, i.e. below 30 points. In the strategy, as in most previous cases, no defense orders were used because the exit from the market took place when the $\% \mathrm{~K}$ line crossed the $\% \mathrm{D}$ line from the top.

Finally, 39 transactions were made under the strategy, 22 of which turned out to be profitable (56.40\%). Gross profit of EUR 189,929 significantly exceeded the gross loss of EUR 114,032, giving a net profit of EUR 75,897. The most profitable transaction earned EUR 24,905 with an average of EUR 8,633. The most losing position was a loss of EUR 31,480, which resulted from the more than 500-point price gap on March 9, 2020. The average losing trade was around EUR 6,708, while the profit ratio was 1.67 and the expected profit per item is EUR 1,946. A slightly different version of the report also allows for a different presentation of the results and provides additional data. 


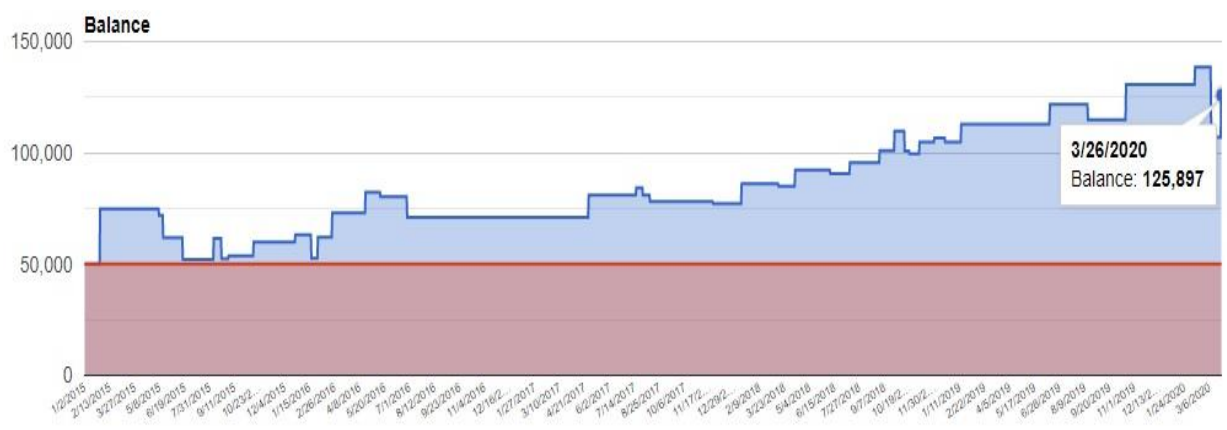

Figure 6. Capital curve for the Keltner Channel - Stochastic strategy

Source: own elaboration.

As we can see, the last strategy at the end of the investment period allowed the investor to enjoy the highest profit with a relatively high percentage of profitable trades. Below is a summary of the strategy's results in absolute terms.

Table 1. Summary of the results of individual strategies

\begin{tabular}{|c|c|c|c|}
\hline Strategy & Lowest balance & Highest balance & Final score \\
\hline 1 & 50000 & 97161 & 97161 \\
\hline 2 & 50000 & 92830 & 58818 \\
\hline 3 & 50000 & 130743 & 123243 \\
\hline 4 & 33875 & 90220 & 60519 \\
\hline 5 & 50000 & 95301 & 83369 \\
\hline 6 & 50000 & 138580 & 125897 \\
\hline
\end{tabular}

Source: own elaboration.

The least profitable system turned out to be the PSAR - MACD strategy although the Ichimoku technique generated a slightly better result, which additionally, in the analyzed period, was the only one that „went down” below the level of initial capital.

\subsection{Comparison of strategies based on the Sharpe index and MAR}

Looking only at the achieved rate of return, the best strategy turned out to be the last one, based on the stochastic oscillator and the Keltner Channel. However, when measuring the effectiveness of the strategy, the risk incurred should be taken into account. The resulting measure of effectiveness is called the risk-adjusted rate 
of return. This concept includes, among others, Sharpe meter. The higher the ratio, the better, as the strategy generated a higher rate of return per risk unit. The Sharpe measure is defined by the following formula [Ormaniec 2019: 32]:

$$
\mathrm{Sh}=\frac{\mathrm{r}-\mathrm{rf}}{\sigma},
$$

where:

$\mathrm{r}$ - the average rate of return on the portfolio,

rf - risk-free rate of return,

$\sigma-$ standard deviation of rates of return.

The value of the indicator itself after adjusting for the incurred risk is not enough to assess the quality of individual strategies, but only serves to compare them [Jajuga 2015: 257]. The indicator is the most frequently used measure of the management efficiency of investment funds, but it can also be successfully used to evaluate transaction systems.

In the study, the average rate of return on the portfolio was taken as the average of the annual rates of return over the full 5 years (thus the first quarter of 2020 was omitted). The most frequently considered risk-free rate is the yield on 10 -year treasury bonds. In the analyzed period, the average profitability of German „10-year-olds” fluctuated around 0\%, therefore, the Sharpe index was adjusted to the quotient of the average annual rates of return and their standard deviation. The results are presented in the table below.

Table 2. Sharpe index for the analyzed transaction systems

\begin{tabular}{|c|c|c|c|}
\hline Strategy & Average annual rate of return & Standard deviation & Sharpe Ratio \\
\hline 1 & $17,3 \%$ & $30,2 \%$ & 0,57 \\
\hline 2 & $11,1 \%$ & $26,1 \%$ & 0,43 \\
\hline 3 & $25,2 \%$ & $41,1 \%$ & 0,61 \\
\hline 4 & $28,2 \%$ & $72,4 \%$ & 0,39 \\
\hline 5 & $14,5 \%$ & $31,0 \%$ & 0,47 \\
\hline 6 & $21,6 \%$ & $10,9 \%$ & 1,98 \\
\hline
\end{tabular}

Source: own elaboration.

The most effective strategy turned out to be the one based on the Keltner Channel and the stochastic oscillator, and the least effective strategy was number 4, i.e. the Japanese Ichimoku technique. 
Another indicator that can be used to compare transaction systems is MAR (Managed Account Ratio). We calculate it as the quotient of two values [www4, accessed 24.04.2020]:

$$
\mathrm{MAR}=\mathrm{CAGR} \% / \operatorname{maxDD} \%
$$

CAGR is nothing more than the rate of capital growth calculated in relation to the initial value and smoothed to annual periods. The denominator of the equation is the maximum percentage of capital drawdown, understood as the distance between the local maximum and minimum on the capital curve during the entire investment period [www9, accessed 24.04.2020]. During the 21 analyzed quarters, the highest MAR was characteristic for strategy no. 3, i.e. based on the Bollinger bands and the RSI oscillator. Strategies 5 and 6 also showed a high reading, while strategy 2 (Parabolic SAR along with MACD) was the worst. The table below presents a list of individual systems.

Table 3. MAR coefficient for the analyzed transaction systems

\begin{tabular}{|c|c|c|c|}
\hline Strategy & CAGR & maxDD & MAR \\
\hline 1 & $13,5 \%$ & $16,4 \%$ & 0,82 \\
\hline 2 & $3,1 \%$ & $18,8 \%$ & 0,17 \\
\hline 3 & $18,7 \%$ & $15,3 \%$ & 1,23 \\
\hline 4 & $3,7 \%$ & $26,7 \%$ & 0,14 \\
\hline 5 & $10,2 \%$ & $9,8 \%$ & 1,04 \\
\hline 6 & $19,2 \%$ & $22,7 \%$ & 0,85 \\
\hline
\end{tabular}

Source: own elaboration.

Based on the data contained in the above tables, it can be concluded that the best strategies turned out to be strategies no. 3 and 6, while the least effective are strategies no. 2 and 4.

Interestingly, the Sharpe and MAR ratios provided information in line with the final balances on the investor's account.

\section{PASSIVE STRATEGY - „BUY AND HOLD”}

An alternative to active investment strategies that use technical analysis is a passive long-term investment strategy based mainly on fundamental analysis. Unfortunately, in the case of stock indices, comparing them is not as easy as it may seem. Well, long-term maintenance of positions on futures or CFDs would 
be associated with very large capital slips. Moreover, the costs of holding positions on contracts for difference would significantly reduce the investor's possible profits. Therefore, when it comes to passive strategies, a better solution is, for example, investments in ETFs, on which active trading is not profitable because both when buying and selling, commissions of about $0.30 \%$ are charged [www10, accessed 27.04.2020].

Despite the slightly different specificity of the instruments corresponding to a given strategy, it is worth looking at how a buy and hold investment would look like in the same investment horizon against the background of previously tested trading systems. The analysis was carried out on the largest, in terms of assets, ETF replicating the DAX index, i.e. iShares Core DAX UCITS ETF, in which all dividends are reinvested [www11, accessed 27.04.2020].

Assuming that the investor purchased the participation units at the beginning of 2015, they had to pay 95 euros for each. During the course of the investment, their value dropped four times below the purchase price, reaching the lowest level of EUR 82 (-13.7\% of the capital invested) in the March panic in 2020. The highest return could have been achieved in January 2018 and February 2020, when the rate was close to EUR 131 (+37.9\%). If the investor decided to sell the units at the end of March 2020, they would receive EUR 95 for each of them, which is the same price as at the start of the investment, after nearly $16 \%$ rebound from this year's minima. In this case, the MAR coefficient would oscillate around 0.

Let us consider one more scenario that ignores the first quarter crash of this year. The unit price (including dividends paid and reinvested) at the end of 2019 was EUR 126.70. With a CAGR of 5.9\% and a maximum 2015-2016 capital draw of $25.8 \%$, the MAR index would show a reading of 0.23 . Sharpe's measure, calculated in the same way as for the 6 tested strategies for a period of full five years, shows the value of 0.43 .

Table 4. Summary of the results of all tested strategies

\begin{tabular}{|c|c|c|r|r|c|}
\hline Strategy & Lowest return & Highest return & Final score & \multicolumn{1}{c|}{ MAR } & Sharpe Ratio \\
\hline 1 & $0,0 \%$ & $94,3 \%$ & $94,3 \%$ & 0,82 & 0,57 \\
\hline 2 & $0,0 \%$ & $85,7 \%$ & $17,6 \%$ & 0,17 & 0,43 \\
\hline 3 & $0,0 \%$ & $161,5 \%$ & $146,5 \%$ & 1,23 & 0,61 \\
\hline 4 & $-32,3 \%$ & $80,4 \%$ & $21,0 \%$ & 0,14 & 0,39 \\
\hline 5 & $0,0 \%$ & $90,6 \%$ & $66,7 \%$ & 1,04 & 0,47 \\
\hline 6 & $0,0 \%$ & $177,2 \%$ & $151,8 \%$ & 0,85 & 1,98 \\
\hline ETF & $-13,7 \%$ & $37,9 \%$ & $0 \% ;(33,4 \%)$ & $0 ;(0,23)$ & 0,43 \\
\hline
\end{tabular}

Source: own elaboration. 
Data with a summary of the active and passive strategies are presented in Table 4.

For ETF investments, figures in parentheses assume unit sales on December 31, 2019.

\subsection{Research summary}

The data presented in Table 3 show that during the research period, only two strategies (Ichimoku and ETF) would produce negative returns at the worst possible end of the investment. At the best moment, the ,passive" investment achieved the lowest result. Looking at the final balance at the end of 2019, as many as 4 systems based on technical analysis were more effective than the „buy and hold" strategy, and at the end of the first quarter of 2020 - all of them. When analyzing the measures of management quality, it turns out that taking into account the 21 quarters, the passive strategy was characterized by the lowest MAR index. The Sharpe's measure is also relatively weak compared to the 4 leading strategies.

In addition, each of the systems achieved a positive rate of return, and losses were only reduced by the previously generated surpluses in as many as 5 out of 6 examined cases. The average profit for a single strategy is EUR 41,500 or 1,660 points.

\section{SUMMARY}

The aim of the article was to test the effectiveness of trading systems built on the basis of technical analysis in 2015-2020 on the DAX stock exchange index. This goal has been achieved, which is confirmed by the results of the research that allow to evaluate the effectiveness of the transaction systems under study in 20152020. On the basis of the transactions carried out, it can be concluded that the technical analysis works in practice and on its basis it is justified to construct investment strategies that can bring profits in the long term while maintaining an appropriate level of risk. It is true that the percentage of unprofitable positions was relatively high, but the generated sell signals made it possible to cut losses quite quickly. As a result, only one of all analyzed capital curves fell below the level of initial capital during the investment period. It is worth noting that additional verification of more parameters for each oscillator, channel or moving average, as well as changing the time interval or other tool combinations, would probably improve the performance of the systems. A comparison against the background of passive investment, both in terms of the quality of portfolio management and the achieved rates of return, is definitely in favor of active strategies. However, due 
to the different specifics of the instruments, it should be approached with a lot of caution.

In the light of the conducted research, it is worth emphasizing that there is no single best transaction system that will always bring above-average rates of return, regardless of the current market situation. Financial markets are characterized by high dynamics of changes, therefore, a strategy that has been successful in recent years may not necessarily prove successful in the future. Moreover, the obtained results indicate that the evaluation of the effectiveness of a given strategy differs depending on the measures used.

Technical analysis is not without its drawbacks. Perhaps it does not discount all information, but only the well-known or foreseeable by the market. The simulations carried out prove that technical analysis is an effective tool for risk management and, in combination with fundamental analysis, increases the probability of success. It is clear that history does not always have to repeat itself, but the psyche of investors has remained unchanged for years.

\section{BIBLIOGRAPHY}

Bąk B., 2015, Skuteczność techniki Ichimoku na przykladzie kontraktów terminowych na indeks WIG20, Uniwersytet Marii Curie-Skłodowskiej, Wydział Ekonomiczny, Lublin.

Borowski K., 2001, Technika Ichimoku (renesans japońskiej techniki inwestowania), „Studia i Prace Kolegium Zarządzania i Finansów", z. 19.

Borowski K., 2017, Analiza techniczna. Średnie ruchome wskaźniki i oscylatory, Difin, Warsaw.

Borowski K., 2018, Metody inwestowania na rynkach finansowych, Difin, Warsaw.

Borowski K., 2019, Efficiency and stability of trading systems based on plain, exponentially and linearly weighted moving averages, „Annales Universitatis Mariae Curie-Skłodowska. Section H-Oeconomia", vol. 53, no. 4.

Czekała M., 1997, Analiza fundamentalna i techniczna, Wydawnictwo Akademii Ekonomicznej im. Oskara Langego, Wrocław.

Elder A., 2018, Zawód Inwestor Gietdowy. Nowe ujęcie, XTB, Poznań.

Elliott N., 2007, Ichimoku Charts. An introduction to Ichimoku Kinko Clouds, Harriman House.

Etzkorn M., 1999, Oscylatory, WIG Press, Warsaw.

Frierdich M., 2013, Hedge Funds. Die Konigsklasse der Investments, FBV, Monachium.

Jabłoński B., 2006, Innowacyjna strategia ograniczajaca ryzyko walutowe, Uniwersytet Ekonomiczny w Katowicach, Katowice.

Jajuga K., 2015, Inwestycje, Wydawnictwo Naukowe PWN, Warsaw.

Kochan K., 2009, Forex w praktyce, Helion, Gliwice.

LeBeau C., Lucas D., 1998, Komputerowa analiza rynków terminowych, WIG PRESS, Warsaw.

Murphy J., 1995, Analiza techniczna, WIG PRESS, Warsaw.

Murphy J., 2017, Analiza techniczna rynków finansowych, Admiral Markets, Poznań.

Nowakowski J., 2003, Normalizacja wskaźników analizy technicznej, „Studia i Prace Kolegium Zarządzania i Finansów”, z. 29.

Ormaniec T., 2019, Możliwość osiagania ponadprzeciętnych stóp zwrotu na podstawie informacji o sprzedaży oraz umorzeniach jednostek uczestnictwa w otwartych funduszach inwestycyjnych, „Studia i Prace Kolegium Zarządzania i Finansów. Zeszyt Naukowy”, nr 173. 
Oziemczuk K., 2011, Ichimoku. Japońska strategia inwestycyjna, Bullet Books, Warsaw.

Pająk A., 2013, Dochodowość inwestycji w kontrakty terminowe na akcje w Polsce, Wydawnictwo Adam Marszałek, Toruń.

Rockefeller B., 2012, Analiza techniczna dla bystrzaków, Wydawnictwo Septem.

Słupek T., 2001, Analiza techniczna. Wprowadzenie, Dom Wydawniczy ABC, Cracow.

\section{Other Internet Sources:}

Cennik Biura Maklerskiego ING Banku Śląskiego, www.ing.pl/indywidualni/inwestycje-ioszczednosci/inwestycje-gieldowe/etf [accessed 27.04.2020].

[www1] www.3sigma.com/whats-so-special-about-3-sigma [accessed 03.03.2020].

[www2] www.admiralmarkets.pl/education/articles/forex-indicators/parabolic-sar-forex [accessed 28.02.2020].

[www3] www.admiralmarkets.pl/education/articles/forex-indicators/wskaznik-cci [accessed 24.04.2020]

[www4] www.blogi.bossa.pl/2008/05/30/miary-oplacalnosci-i-ryzyka-transakcji/ [accessed 24.04.2020].

[www5] www.blogi.bossa.pl/2011/04/22/subiektywizm-analizy-technicznej/ [accessed 02.02.2020].

[www6] www.comparic.pl/category/analizy/indeksy/dax/ [accessed 10.04.2020].

[www7] www.comparic.pl/parabolic-sar-przewodnik-od-tradeciety/ [accessed 30.03.2020].

[www8] www.comparic.pl/tradeciety-wstega-bollingera-najlepszy-wskaznik-wielu-powodow/ [accessed 2.04.2020].

[www9] www.fxmag.pl/artykul/obsuniecie-kapitalu-jak-interpretowac-drawdown [accessed 24.04.2020].

[www10] www.ing.pl/ individual/investment-and-savings/investment-gieldowe/etf [accessed 27.04.2020].

[www11] www.justetf.com/en/how-to/dax-etfs.html [accessed 27.04.2020].

[www12] www.parkiet.com/artykul/1432239.html [accessed 27.03.2020].

[www13] www.parkiet.com/artykul/1433930.html [accessed 15.04.2020].

[www14] www.sii.org.pl/static/img/004366/Podstawy_analizy_Ichimoku.pdf [accessed 15.03.2020].

[www15] www.thebalance.com/how-to-day-with-trade-keltner-channels-4051613

[accessed 20.03.2020].

[www16] www.tms.pl/wskazniki-trendu [accessed 27.02.2020].

[www17] www.tradersarea.pl/kanal-donchiana/[accessed 28.03.2020].

\section{List of abbreviations:}

ADX - Average Directional Movement Index

ATR - Average True Range

CCI - Commodity Channel Index

CFDs - Contracts For Difference

DAX - Deutscher Aktienindex

DI+ - (Directional Indicator +$)$

DI- - (Directional Indicator -)

DMI - Directional Movement Index

ETF - Exchange traded fund

MAR - Managed Account Ratio.

MACD - Moving Average Convergence/Divergence 
MAR - Managed Account Ratio

PSAR - Parabolic Stop and Reversal

SAR - Parabolic Stop and Reversal

SMA - Simple Moving Average

RSI - Relative Strength Index.

Przyjęto/Accepted: 10.11.2020

Opublikowano/Published: 31.12.2020 